University of Massachusetts Amherst

ScholarWorks@UMass Amherst

Masters Theses

Dissertations and Theses

March 2017

\title{
SODIUM REDUCTION IN TURKEY BREAST MEAT BY USING SODIUM ANION SPECIES
}

Janamkumar Pandya

University of Massachusetts Amherst

Follow this and additional works at: https://scholarworks.umass.edu/masters_theses_2

Part of the Food Chemistry Commons, and the Food Processing Commons

\section{Recommended Citation}

Pandya, Janamkumar, "SODIUM REDUCTION IN TURKEY BREAST MEAT BY USING SODIUM ANION SPECIES" (2017). Masters Theses. 481.

https://doi.org/10.7275/9427996 https://scholarworks.umass.edu/masters_theses_2/481

This Open Access Thesis is brought to you for free and open access by the Dissertations and Theses at ScholarWorks@UMass Amherst. It has been accepted for inclusion in Masters Theses by an authorized administrator of ScholarWorks@UMass Amherst. For more information, please contact scholarworks@library.umass.edu. 


\title{
SODIUM REDUCTION IN TURKEY BREAST MEAT BY USING SODIUM ANION SPECIES
}

\author{
A Thesis Presented \\ By \\ JANAM K PANDYA \\ Submitted to the Graduate School of the \\ University of Massachusetts Amherst in partial fulfillment \\ of the requirements for the degree of \\ MASTER OF SCIENCE
}

FEBRUARY 2017

Food Science 
(C) Copyright by Janam Pandya 2017

All Rights Reserved 


\title{
SODIUM REDUCTION IN TURKEY BREAST MEAT BY USING SODIUM ANION SPECIES
}

\author{
A Thesis Presented \\ By \\ JANAM K PANDYA
}

Approved as to style and content by:

Amanda J. Kinchla, Chair

David J. McClements, Member

Eric A. Decker, Member

Eric A. Decker, Department Head Department of Food Science 


\section{DEDICATION}

To my parents, for their direction, support and believing in my all endeavors! 


\section{ACKNOWLEDGMENTS}

I would like to thank my advisor, Professor Amanda Kinchla, for her guidance and oversite in this research project and support throughout my degree. She helped me design this research study and provided her critical thinking. I would also like to thank Professor Eric Decker for his technical guidance and direction in this research. I would like to extend my sincere gratitude to him and Professor Julian McClements for being on the reviewing committee. I am grateful for their helpful recommendation and valuable time.

My very special gratitude to the entire Kinchla lab group for their collaboration and support. My sincere thanks to Naa Ankrah and Kelsey Decker for assisting me in this research. I am glad both of you got valuable learning experience from this project. Your

help in this research was really useful. I would also like to thanks Dave Prodanus for all his help sourcing meat, laboratory consumables and chemicals. 


\title{
ABSTRACT \\ SODIUM REDUCTION IN TURKEY BREAST MEAT BY USING SODIUM ANION SPECIES
}

\author{
FEBRUARY 2017 \\ JANAM PANDYA, B.E. GUJARAT TECHNOLOGICAL UNIVERSITY \\ M.S. UNIVERSITY OF MASSACHUSETTS AMHERST \\ Directed by: Professor Amanda Kinchla
}

\begin{abstract}
Research studies show that an average American consumes 3,400 to 4,500 $\mathrm{mg} /$ day of sodium in their diet against the dietary recommendation of 1,500 to 2,300 $\mathrm{mg}$ /day. The majority of this sodium comes from processed foods. Excess sodium in the diet can potentially cause health issues such as hypertension, heart attack, kidney failure, and bone problems. The objective of this study is to understand sodium diffusion in a protein model using turkey breast meat and determine the opportunities of its reduction by changing the process conditions and combining table salt with other sodium salts.
\end{abstract}

Since proteins are a complicated system and there are very few research studies available on meat in this area, it is necessary to understand the trend of sodium diffusion in the meat while cooking in presence of salt at different temperatures followed by analyzing the change in the diffusion in presence of different sodium salts with anions larger than sodium chloride. Since protein denaturation can have impact on the diffusion 
process, the denaturation profile for turkey breast meat protein was analyzed by Differential Scanning Colorimetry (DSC). The DSC results were visually confirmed by SEM analysis. After obtaining results from DSC and SEM analysis, the processing temperature of $4^{\circ} \mathrm{C}, 23^{\circ} \mathrm{C}, 50^{\circ} \mathrm{C}, 70^{\circ} \mathrm{C}$ and $90^{\circ} \mathrm{C}$ was implemented to obtain the diffusion trend before, during, and after protein denaturation. 1-inch meat cubes were cooked in $5 \%(0.86 \mathrm{M} / \mathrm{L})$ salt solution at different time and temperature combinations. Sodium analysis was performed on Ion Selective Electrode (ISE) and the results were confirmed by ICP-OES. This study showed that the sodium content of the processed samples was not proportional to the treatment temperature.

The Study was also conducted to analyze the effects of sodium salts with larger anions than sodium chloride on sodium diffusion during thermal applications. Sodium Phosphate, Sodium Tripolyphosphate, Sodium Sulfate and Monosodium Glutamate were incorporated in the study. Sodium content in the samples processed in this salts showed $32-46 \%$ reduction compared to those processed in sodium chloride. Since sodium phosphate is widely used in the meat industry, it may have the most potential to partially replace salt. Texture analysis was performed on the samples cooked in sodium chloride and sodium phosphate solutions in order to determine changes in textural properties. A brief sensory test was also conducted with 10 participants to investigate the preference of sodium phosphate incorporation in the meat and to identify any after taste. 


\section{TABLE OF CONTENTS}

Page

ACKNOWLEDGEMENT ..V

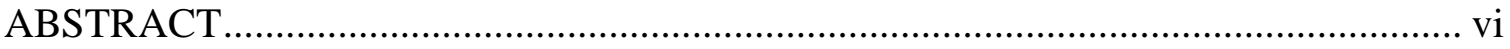

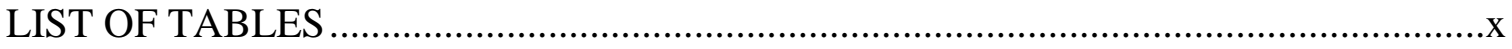

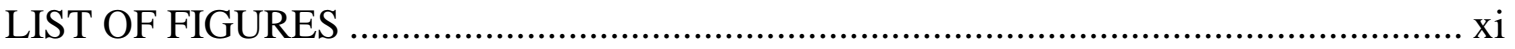

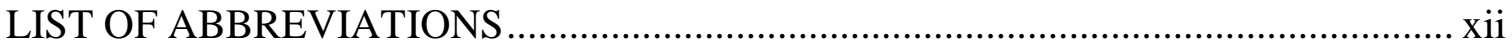

CHAPTER

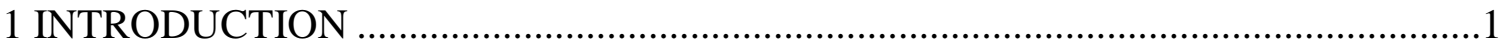

2 LITERATURE REVIEW ..........................................................................

2.1 Sodium Consumption Trends .............................................................

2.2 Health Effects of Excessive Sodium Consumption .......................................5

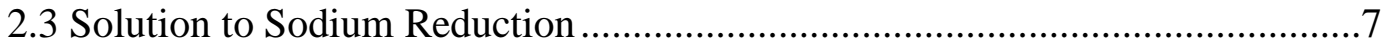

2.4 Sodium in Processed Meat and Poultry ....................................................... 9

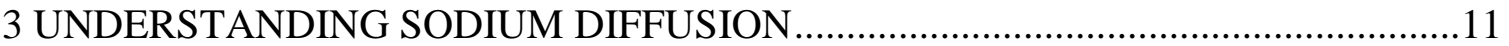

3.1 Protein Model Selection and Sourcing …...................................................11

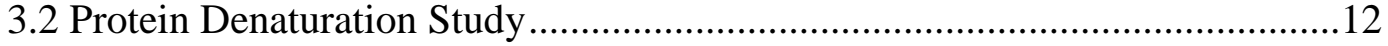

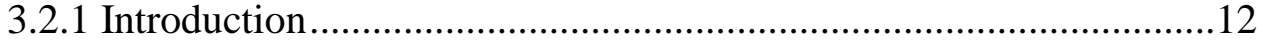

3.2.2 Materials and Method ............................................................12

3.2.3 Results and Discussion ........................................................13

3.3 Scanning Electron Microscopy …........................................................... 14

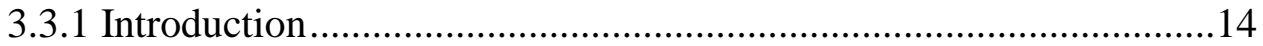

3.3.2 Materials and Method ............................................................14

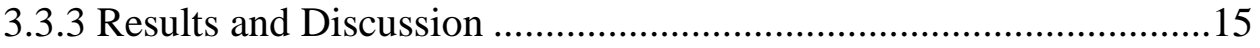

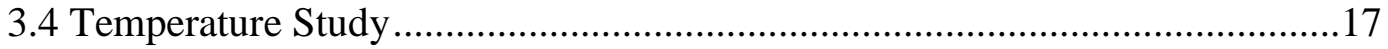

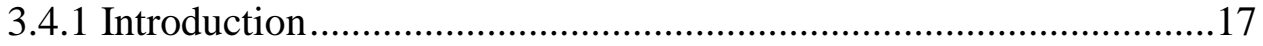

3.4.2 Materials and Method ...............................................................17

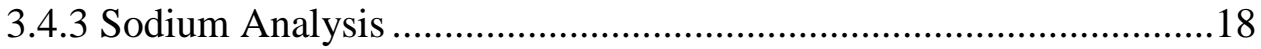

4 EFFECT OF SODIUM SALTS WITH LARGER ANION THAN SODIUM

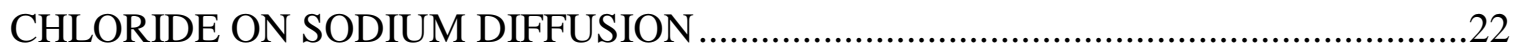

4.1 Calculation of Sodium Diffusion Coefficient ...............................................22

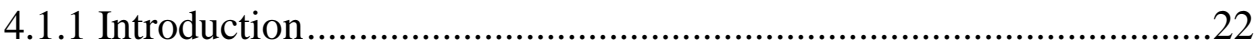

4.1.2 Calculation of Sodium Mass Transfer Coefficient .........................22

4.1.3 Sodium Content of Turkey Breast Meat at Saturation Point ...........23 
4.2 Determining The Effects of Different Sodium Salts Having Anion Larger

Than Sodium Chloride On Sodium Diffusion .................................................24

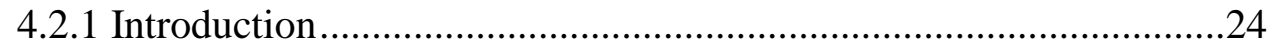

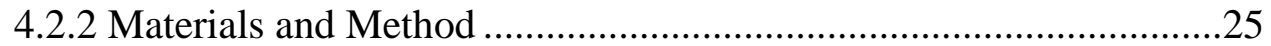

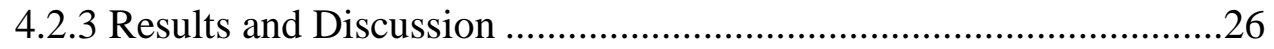

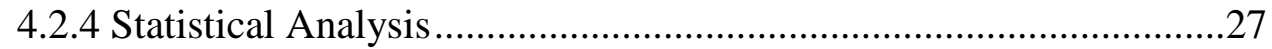

4.3 Texture Analysis ......................................................................................

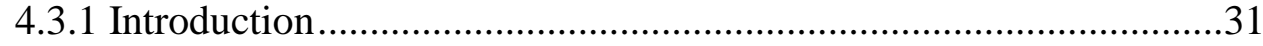

4.3.2 Materials and Method ....................................................................

4.3.3 Results and Discussion ..................................................................32

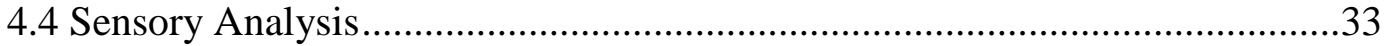

4.4.1 Materials and Method .....................................................................33

4.4.2 Results and Discussion ...................................................................34

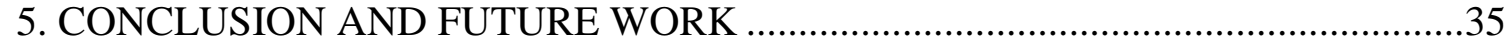

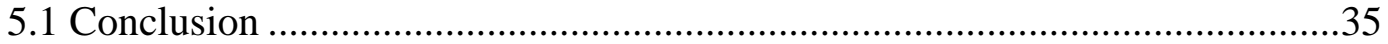

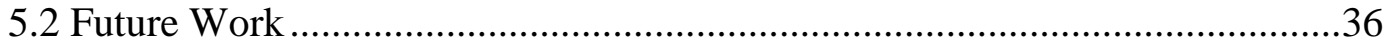

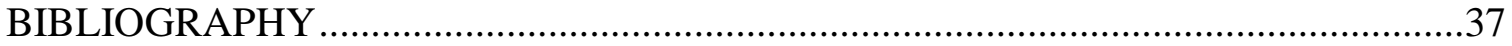




\section{LIST OF TABLES}

Table

Page

4.1. Percentage reduction in the sodium content of final product processed in different sodium salt solutions than that of processed in sodium chloride

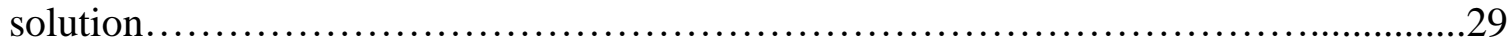

4.2. Mass transfer coefficient, $\mathrm{k}_{\mathrm{s}}\left(\mathrm{min}^{-1}\right)$ values of turkey breast meat at various time points during processing at $90^{\circ} \mathrm{C}$ in different sodium salt solutions................... 30 


\section{LIST OF FIGURES}

Figure

Page

3.1 DSC Thermograph of protein denaturation in turkey breast meat .....................13

3.2. SEM micrograph of raw unprocessed turkey breast meat.................................16

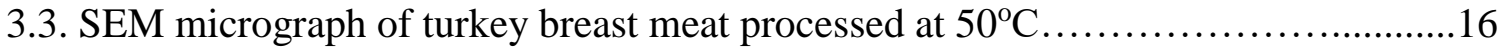

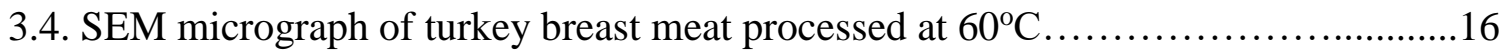

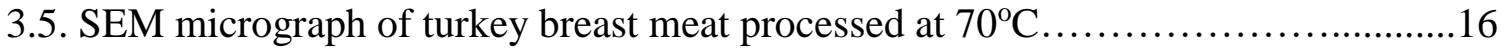

3.6. Sodium content $(\mathrm{mg} / 100)$ of turkey breast meat processed in $0.86 \mathrm{M} / 1$ sodium

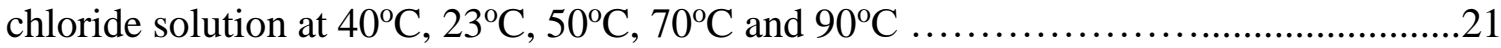
4.1. Comparison Sodium content of turkey breast meat processed in $0.86 \mathrm{M} / 1$ sodium chloride, sodium Tripolyphosphate and sodium phosphate solutions at

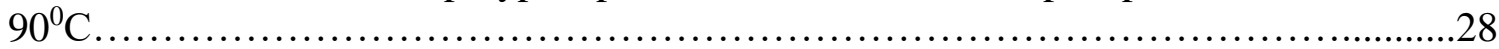

4.2. Sodium content of turkey breast meat processed in $0.86 \mathrm{M} / 1$ sodium chloride, sodium sulfate and monosodium glutamate solutions at $90^{\circ} \mathrm{C}$

4.3. comparison of sodium content of turkey breast meat processed in $0.86 \mathrm{M} / 1$ sodium chloride, sodium phosphate and 50:50 ratio of sodium chloride and sodium phosphate at $90^{\circ} \mathrm{C}$ 30

4.4. Texture profile analysis of turkey breast meat processed at $90^{\circ} \mathrm{C}$ for 40 minutes in sodium chloride and 50:50 molar ratio solution of sodium chloride and sodium phosphate.... 33 


\section{LIST OF ABBREVIATIONS}

USDA - U.S. Department of Agriculture
CDC - Center of Disease Prevention and Control

AHA - American Heart Association

FDA - U.S. Food and Drug Administration

NHANES - National Health and Nutrition Examination Survey

CMC - Canadian Meat Council

BMJ - British Medical Journal

UMass - University of Massachusetts Amherst

MSG - Monosodium Glutamate

DSC - Differential Scanning Colorimetry

SEM - Scanning Electron Microscopy

ISE - Ion Selective Electrode

ICP-OES - Inductive Couple Plasma - Optical Emission Spectrometry

ISA - Ionic Strength Adjuster

AOAC - Association of Official Agricultural Chemists

ANOVA - Analysis of Variance

SAS - Statistical Analysis System 
$\mathrm{NaCl}$ - Sodium Chloride

NaPO4 - Sodium Phosphate

NaSO4 - Sodium Sulfate

Na5P3O10 - Sodium Tripolyphosphate

C5H8NNaO4 - Monosodium Glutamate 


\section{CHAPTER 1}

\section{INTRODUCTION}

The daily recommended intake of sodium for an individual is less than 2,300 $\mathrm{mg}$ per day. While the estimated average intake of sodium for all Americans ages 1 year and older is approximately 3,400 mg per day (USDA, 2015). Higher sodium intakes increase blood pressure thereby increasing risk to cardiovascular diseases, heart failure, and kidney diseases (CDC, 2016). More than $75 \%$ of the sodium Americans consume comes from packaged, processed, store-bought, and restaurant foods (AHA, 2015). Only a small amount of sodium comes from the saltshaker. A clinical study states that sodium contribution by saltshaker in diet is $80 \%$ lower than that comes from cooking applications (Beauchamp, Bertino, \& Engelman, 1987). One of the reasons is, salt from saltshaker remains on the surface of the food and interacts directly with the taste buds. Whereas during processing and cooking a large quantity of salt diffuses inside the food.This is one of the reasons why processed foods are higher in sodium content. Therefore, even small changes in processing conditions could result in decreased sodium levels, which could have a significant impact on public health.

The word "sodium" is different than "salt" but consumers often used them interchangeably. Sodium as a food ingredient has several of uses such as baking, meat curing, canning, pickling, enhancing flavor, preserving, etc. Small amounts of sodium in processed foods also comes from food additives like baking soda and mono sodium glutamate (MSG) which do not contribute to salty taste but still adds to the total sodium 
on the nutritional panel (FDA, 2016). However, reducing sodium in foods comes back to reducing salt as salt still stays as a major contributor to the total sodium in the food.

Reducing salt in diet and adherence to low salt foods is difficult to maintain. A systematic study on the effects of a reduced sodium diet showed that $69 \%$ of participants reported inconvenience and difficulty with adherence to the reduced sodium diet (Hooper, Bartlett, Smith, \& Ebrahim, 2002). To address this problem, strategies involving sodium reduction during processing or cooking of food may impart an impressive effect on the larger population. One of the current strategies commonly used in food industry is using salt replacers like potassium chloride, calcium chloride, or magnesium chloride. These additives contribute to salty flavor but also tastes bitter and metallic, which limit their current use in food manufacturing. These non-sodium cations activate second type of salt taste $\mathrm{ENaC}$ which is believed responsible for off-taste and flavor (Liem, Miremadi, \& Keast, 2011).

The present study focuses on combining sodium-cation compounds having relatively larger anions with sodium chloride in an osmotic solution. Larger molecules have tendency to diffuse slower in an osmotic solution. Several researchers have previusly studied sodium diffusion in the model food systems in sodium chloride osmotic solution (Graiver, Pinotti, Califano, \& Zaritzky, 2006; Hinkley, Pandya, Kinchla, \& Decker, 2015; Liem et al., 2011; Villacis, Rastogi, \& Balasubramaniam, 2007). Food kept in an osmotic solution shows semi-permeable nature and allows solvent diffusion in and out of the system depending upon the concentration gradient. The diffusion characteristics of sodium chloride in various meat and poultry have been studied by several researchers (Graiver, Pinotti, Califano, \& Zaritzky, 2009; Telis, Romanelli, 
Gabas, \& Telis-Romero, 2003; Volpato, Mechielin, Ferriera, \& Petrus, 2007). However, effect of sodium cation compounds having associated anions larger than chloride on diffusion rate is not been investigated thoroughly. A study conducted on potatoes utilizing larger molecular weight sodium salts reported a lower diffusion rate in the starch models (Hinkley et al., 2015).

Meat and poultry is naturally low in sodium, however, processed meat and poultry are one of the highest sources of sodium in American diets. Processing techniques that incorporate high sodium include brining, curing, marinating, canning, etc. Turkey is one of the most consumed processed meats in America. According to the North American Meat Institute, total turkey meat market in 2013 was 5.8 billion pounds. A recent report of the National Turkey Foundation forecasts and increase in per capita turkey meat consumption from 16 pounds to 20 pounds by 2020 (National Turkey Foundation, 2014). According to a study by Mintel, turkey meat has a 32\% share in the breakfast and lunch meat category. Turkey meat has not been studied widely and has a potential scope of research. Therefore, this research uses turkey breast meat as a protein model to fill critical research gaps and investigate a protein food model to develop a sodium reduction strategy by limiting diffusion rates. 


\section{CHAPTER 2}

\section{LITERATURE REVIEW}

\subsection{Sodium Consumption Trends}

The excessive level of sodium in the diet is not a recently raised concern. The history of salt/sodium consumption is worth noticing. According to a report on salt consumption history by The Salt Institute, the daily salt consumption in western societies was between $15-17 \mathrm{~g}$ which contributes to $6,000-7,000 \mathrm{mg}$ of sodium per day in the early 1800s until the end of World War II (Satin, 2014). After World War II, refrigeration systems came into place and that started replacing salt as a means of preservation. The salt consumption dramatically dropped to nine grams per day which contributes to 3,700 mg of sodium per day. This drop was observed without any pressure or influence from government dietary guidelines or public health institutions recommendations. After this drop, this salt consumption rate has not been changed in fifty years (Satin, 2014).

There have been some recent studies and surveys conducted to demonstrate average sodium consumption trends by public health organizations and research journals. A twenty-two year study was conducted to establish sodium consumption trends in Minnesota. The study was conducted from 1985 to 2009 amongst 10,863 participants between ages 25 and 74. The intake of sodium was estimated from one 24-hour dietary recall. The study concluded that despite long-standing public health recommendations to limit sodium intake to less than $2,300 \mathrm{mg} /$ day, high sodium intake levels persisted over 22 years (Meyer et al., 2013). The daily sodium consumption during this study ranged from 3,249 to 3,968 mg/day. According to one more report, the CDC analyzed sodium 
consumption data of 34,916 participants from 2003 to 2010 collected by the National Health and Nutrition Examination Survey (NHANES). The study indicated that the daily sodium consumption declined slightly from 2003 to 2010 (3,518 to 3,424 mg/day). However, between 2007 and 2010, 79.1\% of U.S. children aged 1-3 years and 95.4\% of U.S. adults ages 19 to 50 consumed higher sodium intake than the daily recommended intake (CDC., 2013).

Higher sodium content in the diet has been reported since early 1800s. One dramatic decline was noticed after World War II due to the introduction of refrigeration systems to preserve food. In spite of this decline, sodium consumption values have stayed much higher than the recommended values. There have been efforts in a variety of studies to find ways to reduce sodium in the diet. Public awareness and campaign was conducted by public health organizations such as the Center of Diseases Prevention and Control (CDC) and the American Heart Association (AHA). A special recommendation and consideration was given on ways to reduce sodium in the diet in the dietary guidelines document of 2010 and 2015 published by USDA. However even with these efforts, the daily sodium intake by an average American is still approximately double recommended daily intake value.

\subsection{Health Effects of Excessive Sodium Consumption}

Sodium is a micronutrient and a macro mineral required by human body to perform various functions. The most important role of sodium is to control blood pressure and blood volume. A human body also requires sodium for the muscles and nerve to function properly. Sodium is a mineral that carries an electrical charge and act as an electrolyte. Sodium in combination with potassium also plays important role to maintain 
normal water balance in the body. It also contributes to the maintenance of concentration and charge differences across cell membranes. Sodium also plays a role in nutrient absorption and transportation process in small intestine. Absorption of sodium also helps absorption of chloride, amino acids, glucose and water. It also helps in the reabsorption of these nutrients after getting filtered from the blood in the kidney.

However, there are certain serious side effects of excessive consumption of sodium. The USDA recommended daily intake of sodium ranges from 1,500 to 2,300 mg/dayr. However, the average American consumes much higher levels than the recommendation. Excessive consumption of sodium leads to serious problems and fatal situations. According to the $\mathrm{CDC}$, heart disease is the leading cause of death in America and excessive consumption of sodium directly impacts blood pressure and normal heart functions. The American Heart Association states that one third of the American population currently has blood pressure and $90 \%$ of American adults are expected to develop high blood pressure in the future (AHA, 2016). Excessive sodium in the bloodstream pulls water into the blood vessels thereby increasing the pressure. Over time, high pressure in the blood stream stretches and injures blood vessel walls and builds a plaque, which blocks the vessels. This situation causes more pressure to the heart function that can lead to a stroke. The American Heart Association also states that excessive sodium consumption may lead to heart failure, stroke, enlarged heart muscle, stomach cancer, kidney disease, and osteoporosis. Too much sodium consumption also increases water retention in the body, which may result in puffiness, bloating, and weight gain (AHA, 2016). 
A systematic review and meta-analysis of prospective studies published in the British Medical Journal (BMJ) studied the relation between salt intakes and stoke or total cardiovascular diseases. The review considered 19 independent cohort samples from 13 studies with $1,77,025$ participants. The results from the review concluded that higher salt intakes were associated with greater risks of stroke and cardiovascular diseases at $95 \%$ confidence level without any significant publication bias (Strazzullo, D’Elia, Kandala, \& Cappuccio, 2009). Whereas another study published in the same journal looked at the long term effects of dietary sodium reduction on cardiovascular diseases outcomes. The study used 3,126 participants ages 30 to 54 years were kept on sodium reduction intervention or control for 18 to 48 months. The study concluded that the risk of the cardiovascular event was $25 \%$ lower in the intervention group (Cook et al., 2007).

\subsection{Solution to Sodium Reduction}

More than $75 \%$ of the sodium Americans consume comes from packaged, processed, store-bought, and restaurant foods (AHA, 2015). More than $40 \%$ of this sodium is contributed by the following top 10 products: bread and rolls, cold cut and cured meat such as turkey and ham, pizza, fresh and poultry, soups, sandwiches and cheeseburgers, cheese pasta, meat mixed dishes, snacks such as potato chips, pretzels and popcorn (CDC, 2016). Sodium plays various functions in different processed foods. Sodium in the form of salt or MSG is used to add salty taste or to enhance flavor. Sodium in the form of salt is used widely in pickling and canning industries as a preservative. It

preserves freshness and increases the shelf life of the product by retarding microbiological growth. Sodium plays a big role in improving texture and appearance. It 
also helps retain moisture in processed meat products. Finally, it stabilizes texture and helps bread rise and cheese to stick together (CDC, 2012).

Since sodium is contributed from various sources and has variety of functions to play, it is difficult to reduce or remove sodium from processed foods. There have been many research efforts conducted to develop sodium reduction strategies in processed food products. There are several methods and solutions currently used in the food industry to reduce sodium content in processed food, however with little success in terms of consumer acceptance. Simply reducing salt content in food to achieve less sodium did not achieve consumer acceptance due to compromises in the salty taste of the food (Geller, 2011). Another alternative approach to reduce sodium is the use of salt enhancers and replacers. Monosodium Glutamate (MSG) is a potential salt enhancer. However, research shows MSG has negative health effects including carcinogenic effect and consumer intolerance. Other salt enhancers used are autolyzed yeast and hydrolyzed protein bases such as soy sauce. These enhancers are quite successful and are clean label however; their use is limited to certain types of products as they contribute stronger characteristic taste, flavor, and color to the product. Ginger oil, onion powder, rice flour, and seaweed are also used as salt enhancers in small applications.

Potassium chloride, calcium chloride, and magnesium sulfate are some known salt replacers accepted and used in the food industry. Most commercially available salt substitutes use potassium chloride to partially replace sodium chloride. As these compounds contribute to salty taste, they also impart unfavorable metallic and bitter aftertaste. These compounds activate $\mathrm{ENaC}$ salt taste, which is responsible for off-taste (Liem et al., 2011). Advanced research finding optimizes sodium ions release rates to the 
taste buds to achieve maximum taste receptor simulation through modifying the product structure (Busch, Youg, \& Goh, 2013). Some research has also been conducted on changing salt crystal size and shape. Research shows that small and hollow crystals dissolve faster and gives desired saltiness while lowering salt content (Shepherd, Wharf, \& Farleig, 1989). Limited research has been conducted on these are novel techniques.

In general, through research has not been conducted on unique solutions to replace or reduce sodium in the processed foods.

\subsection{Sodium in Processed Meat and Poultry}

Meat and poultry naturally are not a significant source of sodium in the diet. Sodium is being added to processed meat and poultry products from various sources to play different functions. Processed meat can be preserved by curing, salting, smoking, drying, or canning. The processed meat category includes products like: sausage, hot dog, salami, bacon, ham, cured meat, deli meat, turkey, canned meat, and poultry (Arnason, 2015). The majority of the sodium in the processed meat and poultry products comes from salt. Salt is added to meat products to lower the water activity in order to retard the microbial growth or bacteria like Listeria monocytogenes, Salmonella, Clostridium botulinum, etc. Salt also slows down the rate of chemical reactions. Sodium also helps to bind meat protein together in processed meat products. Salt also increases water-binding capacity of meat during cooking thereby improving the texture, tenderness, and palatability of the final product (CMC).

For a simple comparison, three ounces of raw turkey breast meat contains $54 \mathrm{mg}$ of sodium whereas the same amount of deli turkey meat has 1,020 mg of sodium, which 
is approximately 20 times more compared to raw meat (Braverman, 2016). There is a significant gap in the research in finding a way to significantly reduce sodium content in processed meat products. This research focuses on turkey breast meat as a protein model to examine sodium reduction strategy by combining sodium chloride with other sodium salts with relatively larger molecular weight thereby, reducing sodium diffusion rates. This research can be applicable to most meat processing applications including thermal processing like commercial cooking and canning. 


\section{CHAPTER 3}

\section{UNDERSTANDING SODIUM DIFFUSION}

\subsection{Protein Model Selection and Sourcing}

Turkey breast meat was selected as a protein model to carry out sodium diffusion experiments due to its growing consumption trend and lack of sufficient research. Skinless and boneless turkey breast (White Broad Breasted Domesticated Turkeys, 130140 days old) meat was sourced from a local supermarket (Whole Foods Market, Hadley, MA). The fresh meat was sourced in 5-pound batches and transferred to the Chenoweth Laboratory on the UMass Amherst campus. Upon receiving, the meat was immediately cut into cubes (1x1x1 inche) using a knife (G-2 8 inch, Global, Yoshikin, Japan) to maintain consistent cube shape and diffusion. The cubes were placed on a plastic tray, covered with plastic film, and stored at $-40^{\circ} \mathrm{C}$ in a chest freezer (Model no. PR40-17, SoLo environmental equipment co. Inc., Cincinnati, OH, USA) in the pilot plant to minimize any biological and microbiological changes. All the samples were utilized in 15-day timeframe. Before experiment use, the meat cubes were transferred to a refrigerator (Master Bilt, Fusion series, New Albany, MS) located in the pilot plant at $4^{\circ} \mathrm{C}$ for 16 hours and then equilibrated to room temperature for 45 minutes (Villacis et al., 2007). Upon thawing, the samples were quickly rolled over on an absorbent paper to remove surface moisture and weighed immediately. 


\subsection{Protein Denaturation Study}

\subsubsection{Introduction}

To design the experiments and understand diffusion mechanism in turkey breast meat, it is necessary to understand the denaturation characteristic of the important meat proteins. This study was conducted using Differential Scanning Colorimetry (DSC). The principle of the DSC is to measure the heat effects associated with phase transition and chemical reaction as a function of temperature. In this set of experiments, DSC measures the change in heat flow at a particular temperature at which protein denaturation occurs. Three important proteins; myosin, actin and collagen were studied. These proteins are responsible for characteristic quality attributes of meat such as juiciness, tenderness, and water holding capacity (Tornberg, 2005).

\subsubsection{Materials and method}

The experiments were performed on DSC (Model no. Q100, TA Instruments, New Castle, DE, USA) in Dr. McClements lab in the Chenoweth laboratory. The meat samples were equilibrated at room temperature and an 8-9 $\mathrm{mg}$ portion of the sample was obtained from the center of the cube. These samples were placed in special aluminum pans (Part no. 900793.901, TA Instruments, New castle, DE, USA) and hermetically sealed (Part no. 900794.901, TA Instruments, New castle, DE, USA). Proper contact between the sample and the bottom of the pan was assured in order to allow efficient heat transfer. Upon sealing, the pans were carefully inspected for any sample leakage. Empty hermetically sealed pan was used as blanks. Both sample and blank pans were carefully placed in the instrument chamber using tongs. The experiments were conducted over a 
temperature range of 30 to $100^{\circ} \mathrm{C}$. The heating rate was adjusted to $5^{\circ} \mathrm{C} / \mathrm{min}$. A DSC thermograph was obtained from the software at the end of analysis.

\subsubsection{Results and Discussion}

Figure 3.1 represents a DSC thermograph of turkey breast meat. The first transition in the curve with maximum point at $57.2^{\circ} \mathrm{C}$ is attributed to myosin (Wright, Leach, \& Wilding, 1977), the maximum point in the second curve at $64.9^{\circ} \mathrm{C}$ represents collagen and sarcoplasmic protein denaturation ((Voutila, Ruusunen, Jouppila, \& Puolanne, 2009), and the maximum point in the third curve at $77.3^{\circ} \mathrm{C}$ represents actin denaturation (Wright et al., 1977). These values are close to the values in studies conducted on other meats and fall within the range of the general trend (Graiver et al., 2006; Tornberg, 2005; Voutila et al., 2009; Wright et al., 1977). The results were visually confirmed by using Scanning Electron Microscopy (SEM). Depending upon these results the temperature study experiments included 50,70 and $90^{\circ} \mathrm{C}$ to determine the effect of denaturation on the rate of sodium diffusion.

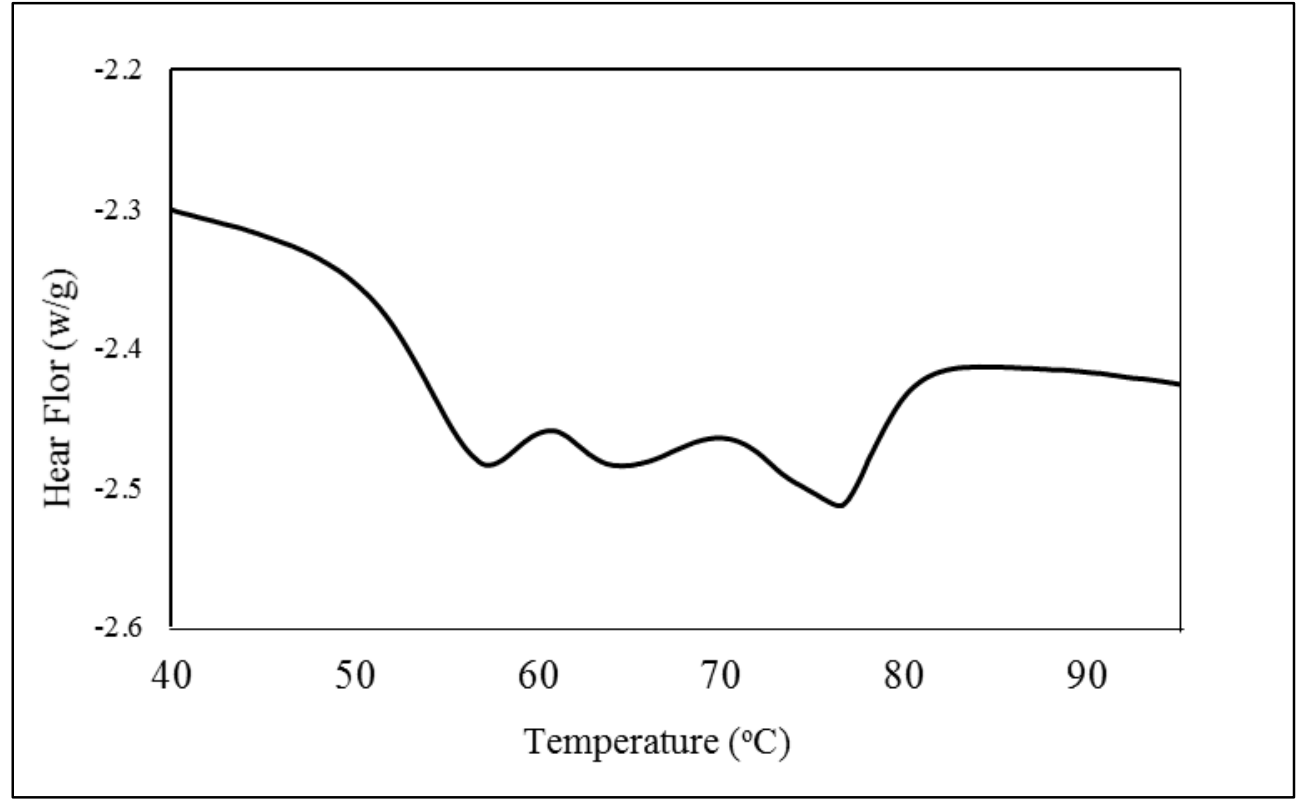

Figure 3.1. DSC Thermograph of protein denaturation in turkey breast meat 


\subsection{Scanning Electron Microscopy}

\subsubsection{Introduction}

Scanning Electron Microscopy (SEM) is a type of electron microscopy that produces an image of the specimen by scanning it with a focused beam of electrons. The electrons interact with the atoms in the sample and produces signals containing information about the sample's surface and composition which are detected to produce the image. In this study, SEM provides the visual confirmation of the protein denaturation results obtained by DSC. It also provides information about the structural changes occurring in the protein tissues due to the effect of denaturation. The samples were cooked over the protein denaturation temperature range obtained from DSC results and were analyzed for SEM images and compared to the raw meat.

\subsubsection{Materials and method}

The meat cubes were processed at 50,60 and $70^{\circ} \mathrm{C}$ in a water bath (Model No. 2872, Precision water bath, Thermo Scientific, Waltham, MA) for 40 minutes. Upon cooking, the samples were rolled over an absorbent paper and allowed to cool. Once cooled, these samples were placed in separate freezer bags and stored in a $-40^{\circ} \mathrm{C}$ chest freezer in the pilot plant for at least 24 hours. Then the samples were freeze-dried for at least 24 hours in a freeze dryer (Model no. 274456, The Virtis Company INC, Gardiner, $\mathrm{NY}$ ) in the pilot plant to minimize structural changes. The samples were then analyzed

for microscopy. Raw unprocessed meat cube was also freeze-dried and analyzed as a control sample. 
A small thin piece from the center of the sample was cut and mounted on an aluminum stub using double-coated carbon conductive tape $(12 \mathrm{~mm}$ x $20 \mathrm{~mm}$, Ted Pella, Redding, CA, USA). The samples were gold-coated using a cressington sputter coater (Model no. 7002-8, Ted Pell, Redding, CA, USA). Sputter coating is a process of applying an ultra-thin coating of conductive metal such as gold onto a non-conductive specimen. Sputter coating prevents charging of the specimen, which can occur because of the static electric field generated in SEM. It also increases signal to noise ratio thereby improving the imaging of the sample. The samples were gold coated for 30 seconds to get $10 \mathrm{~mm}$ of gold coating on the surface. The samples were then analyzed for the microscopy.

The microscopic observations were made using a scanning electron microscope (JCM-6000, JEOL, Japan). The samples were carefully placed on the holder in the instrument chamber and the holder position was aligned appropriately in order to receive focus on the sample. Upon stabilization, the instrument shows the surface image of the specimen on the computer. The image was then zoomed in to appropriate distance using the zooming tabs in the software. The focus on the instrument was adjusted using the autofocus and fine focus tabs. The brightness and contrast level was balanced before taking final image. The final image was scanned by clicking the camera icon in the software and the image was saved in .jpeg format.

\subsubsection{Results and discussion}

Figure 3.2 to 3.5 shows micrograph obtained for different turkey breast samples using SEM. Figure 3.2 represents the micrograph of the control raw turkey breast sample whereas figures $3.3,3.4$ and 3.5 shows the micrograph of the samples processed at $50^{\circ} \mathrm{C}$, 
$60^{\circ} \mathrm{C}$ and $70^{\circ} \mathrm{C}$ respectively. The samples processed at $60^{\circ} \mathrm{C}$ and $70^{\circ} \mathrm{C}$ (figure 3.4 and 3.5) shows difference in the myofibril structure in comparison with control (figure 3.2). The tissue structure of the sample processed at $50^{\circ} \mathrm{C}$ (figure 3.3) looks intact and comparable to the micrograph of raw meat. The samples processed at $60^{\circ} \mathrm{C}$ and $70^{\circ} \mathrm{C}$ were ruptured and fragmented due to the effect of protein denaturation. These images visually confirmed the denaturation of proteins in the temperature range of 60 to $70^{\circ} \mathrm{C}$. Based on the results obtained from SEM and DSC analysis the sodium diffusion experiments were designed.

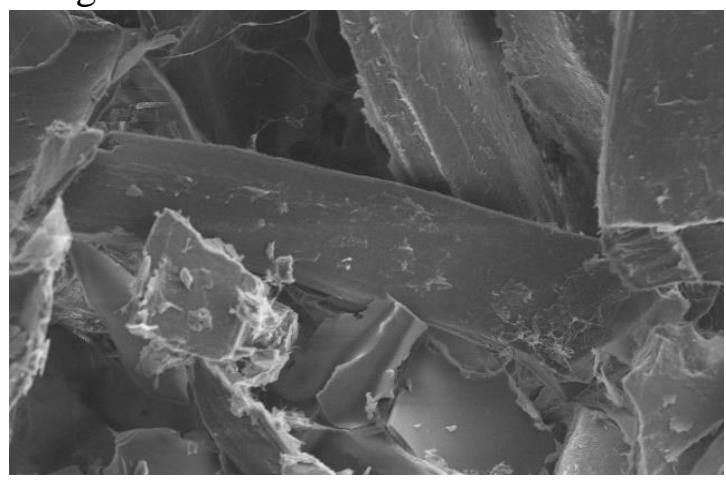

Figure 3.2

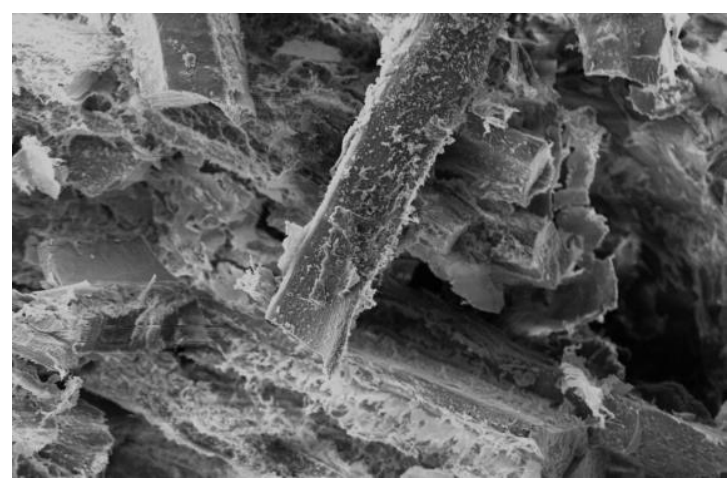

Figure 3.4

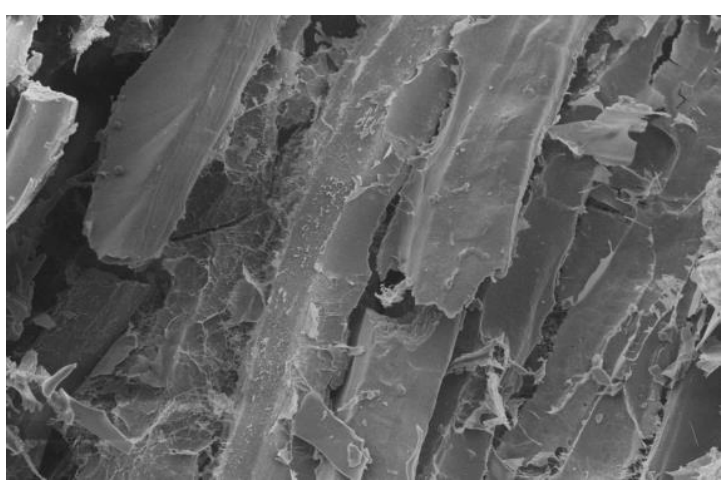

Figure 3.3

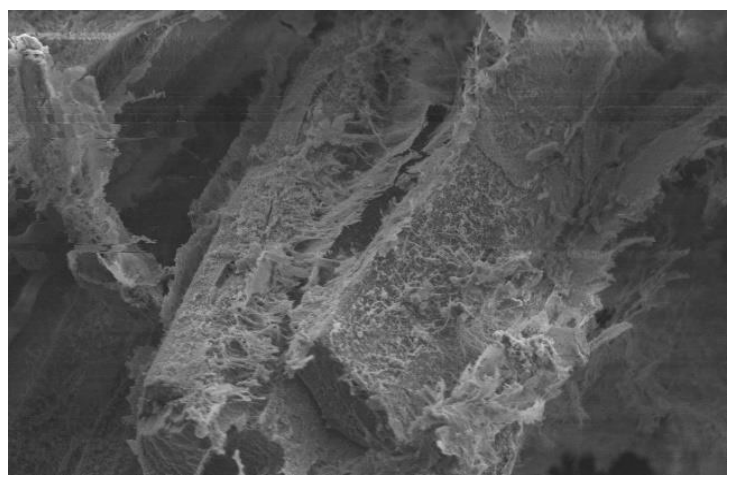

Figure 3.5

Figure 3.2. SEM micrograph of raw unprocessed turkey breast meat. Figure 3.3. SEM micrograph of turkey breast meat processed at $50^{\circ} \mathrm{C}$. Figure 3.4. SEM micrograph of turkey breast meat processed at $60^{\circ} \mathrm{C}$. Figure 3.5. SEM micrograph of turkey breast meat processed at $70^{\circ} \mathrm{C}$. 


\subsection{Temperature Study}

\subsubsection{Introduction}

The first part of this research focused on reducing sodium diffusion in a starch model using potatoes (Data not shown). The experiments were conducted over a temperature range below and above the gelatinization point of starch to understand the effect of gelatinization on the diffusion rate. The results showed that as the temperature increases, rate of sodium diffusion increases because due to the swelling and gelainization of starch molecules (Hinkley et al., 2015). Similar to the starch model experiments, the experiments in this study were conducted at various temperature points to understand the effect of denaturation on sodium diffusion in protein model in order to establish the trend between denaturation and sodium diffusion.

Based on the results from DSC and SEM analysis, we decided to conduct sodium diffusion experiment over a various temperature points below and above the denaturation points of meat proteins. The study was designed over the temperature range of $4,23,50$, 70 , and $90^{\circ} \mathrm{C}$. The reason behind conducting experiments at $4^{\circ} \mathrm{C}$ was to focus the brining and curing aspect of meat processing. The study was also conducted at $23^{\circ} \mathrm{C}$ to understand the diffusion rates at room temperature.

\subsubsection{Materials and method}

Turkey breast cubes were thawed appropriately, rolled over the absorbent paper and weighed. The experiments were conducted in $400 \mathrm{ml}$ Erlenmeyer flask filled with appropriate amount of 0.86M/l (50 g/l) sodium chloride (Fisher Scientific, Fair Lawn, NJ, USA) solutions. The sample to solution ratio was maintain as 1:10 to create effective 
concentration gradient. The experiments at $4^{\circ} \mathrm{C}$ temperature were conducted in a refrigerator (Master Bilt, Fusion series, New Albany, MS) whereas those above room temperatures $\left(50,70\right.$ and $90^{\circ} \mathrm{C}$ ) were conducted in hot water bath (Model No. 2872, Precision water bath, Thermo Scientific, Waltham, MA). The flasks with sodium chloride solution were put in the water bath and refrigerator for respective experiments and allowed to reach the desired temperature before introducing the meat cubes. Once the desired temperature was achieved, meat cubes were dropped in the flask, shook well and was closed with loose stoppers to minimize the change in the concentration due to solvent evaporation. Agitation rate of 70 oscillations per minute was applied to reduce temperature and sodium gradients in the flask (Hinkley et al., 2015). The samples were pulled out every 40,100 and 160 minutes. Upon removal, the samples were rolled on the absorbent paper again to get rid of excess moisture and solution from the surface, allowed to cool for 15-20 minutes, weighed and analyzed for total sodium content. Each set of tests were performed in triplicates.

\subsubsection{Sodium analysis}

Sodium analysis was conducted following AOAC method no. 976.25. The weighed turkey cubes were blended in $100 \mathrm{ml}$ of water for 60 seconds using the blander (Magic bullet $\odot$, Altrincham, UK). The blended sample was strained through the strainer in a $500 \mathrm{ml}$ volumetric cylinder. The meat tissues retained over the strainer was washed again in the cylinder with $50 \mathrm{ml}$ distilled water and pressed with a spatula to make sure maximum sodium is extracted in the water. The retained meat tissues were discarded and the strained solution was diluted up to $500 \mathrm{ml}$ by adding distilled water. The diluted solution was shaken well and $100 \mathrm{ml}$ was used for the sodium content measurement. 
Sodium analysis of all the samples was performed in house using sodium Ion Selective Electrode (ISE) (Model no. 8611BNWP, Thermo scientific orion, Waltham, MA, USA) attached to a millivolt meter (Orion star A214, Thermo scientific orion, Waltham, MA, USA) because of its ease of use and lower cost of analysis The ISE electrode was calibrated by measuring the slope every day before the analysis. The slope analysis was performed using $1000 \mathrm{ppm}$ sodium standard (841108, Thermo scientific orion, Waltham, MA, USA). The slope value was in the range of -54 to -66 . Upon receiving satisfactory slope value, the sodium analysis experiments were conducted.

The electrode was washed with distilled water and dried properly with Kimwipes ${ }^{\circledR}$ before using for the sodium analysis. $100 \mathrm{ml}$ of the strained and diluted sample solution was transferred in $250 \mathrm{ml}$ beaker. $10 \mathrm{ml}$ of Ionic Strength Adjustor (ISA) was added to the sample before the analysis to reduce the interference in the $\mathrm{mV}$ readings. The electrode was dipped into the solution and the $\mathrm{mV}$ reading was observed. The solution was stirred with the self-stirring probe (Model no. 096019, Thermo scientific orion, Waltham, MA, USA) in order to assure the homogeneity of the solution. Once the reading was stabilized, it was logged in the log sheet. $10 \mathrm{ml}$ of the sodium known addition standard (841109 Thermo scientific orion, Waltham, MA, USA) was added to the same beaker and the $\mathrm{mV}$ reading was observed again. All the measurements were conducted in duplicates and the mean value was reported. The sodium content was then calculated using the following formula.

$$
c_{u}=c_{s}\left[\frac{v_{s}}{v_{u}+v_{s}}\right]\left[10^{\Delta E / S}-\frac{v_{u}}{v_{s}+v_{u}}\right]^{-1}
$$


Where,

$\mathrm{C}_{\mathrm{u}}=$ sodium content in sample;

$\mathrm{C}_{\mathrm{s}}=$ Sodium content of the known standard;

$\mathrm{V}_{\mathrm{s}}=$ Volume of the standard;

$\mathrm{V}_{\mathrm{u}}=$ Volume of the sample;

$\Delta \mathrm{E}=$ Change in electrode potential in $\mathrm{mV}$;

$\mathrm{S}=$ Slope of the electrode in $\mathrm{mV}$

\subsubsection{Results and discussion}

Turkey breast samples were cooked at $4,23,50,70$ and $90^{\circ} \mathrm{C}$ in $0.86 \mathrm{M} / \mathrm{L}$ salt solution and analyzed for sodium content using ISE. The results were confirmed by conducting an independent third party laboratory analysis (WBA analytical laboratories, Springdale, AR) by using ICP-OES. The results from both analyses were compared and statistical analysis was performed using ANOVA test in SAS (SAS institute Inc., cary, NC, USA). At $95 \%$ confidence level, there was no significant difference $(p>0.05)$ found between both the results.

Figure 4.6 represents the trend of sodium diffusion in the turkey breast meat over a processing time of 160 minutes at different temperatures. Plotting a line graph of all the treatments together, visually shows slight increase in the sodium content as increase of treatment temperature. Conducting a statistical analysis using ANOVA test in SAS shows that the date is not significantly different $(\mathrm{p}>0.05)$ across all the treatment temperatures. Conducting Duncun test as an extension of Anova showed statistical difference between 
sampling time in a particular treatment but did not show any statistical difference between the treatment points. This study concludes that increase in the treatment temperature and denaturation in protein does not make any significant increase or decrease in the sodium content of the final product. This may be a result of a strong protein and sodium interaction due to their opposite charges.

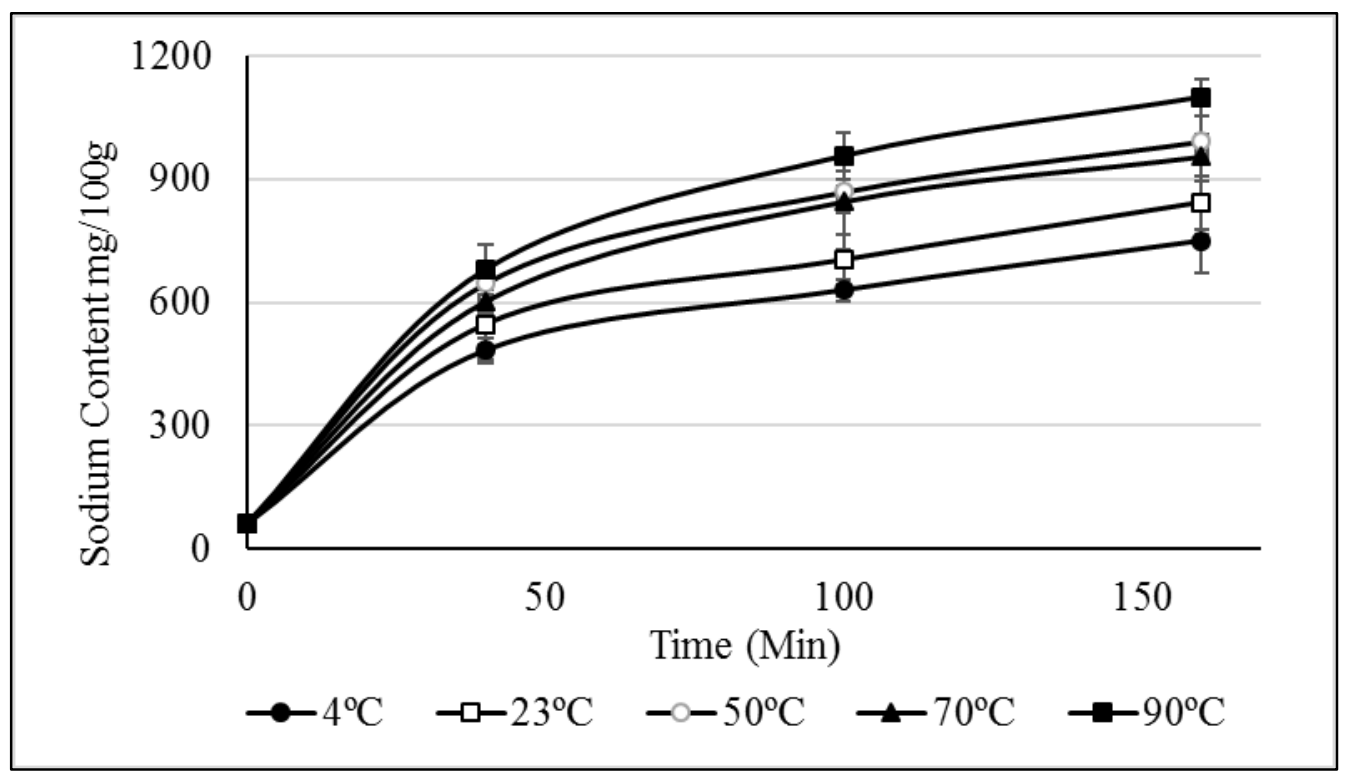

Figure 3.6. Sodium content $(\mathrm{mg} / 100)$ of turkey breast meat processed in $0.86 \mathrm{M} / 1$ sodium chloride solution at $40^{\circ} \mathrm{C}, 23^{\circ} \mathrm{C}, 50^{\circ} \mathrm{C}, 70^{\circ} \mathrm{C}$ and $90^{\circ} \mathrm{C}$ 


\section{CHAPTER 4}

\section{EFFECT OF SODIUM SALTS WITH LARGER ANION THAN SODIUM CHLORIDE ON SODIUM DIFFUSION}

\subsection{Calculation of Sodium Diffusion Coefficient}

\subsubsection{Introduction}

Diffusion is a chemical process of molecules moving from an area of higher concentration to an area of lower concentration. The simplest understanding of diffusion is given by Fick's laws, developed by Adolf Fick's in $19^{\text {th }}$ century.

Fick's first law of diffusion is: The molar flux due to diffusion is proportional to the concentration gradient.

Fick's second law of diffusion: The rate of change of concentration at a point in a space is proportional to the second derivative of concentration with space.

In the mass transport experiments, the flux due to diffusion is given by Fick's first law, only depends on a single property of the solute's interaction with solvent: the diffusion coefficient.

\subsubsection{Calculation of sodium mass transfer coefficient}

For a cubical identity, considering equilibrium approach to mass transfer, the following equation can be written for sodium mass transfer (Rastogi \& raghavarao, 2004):

$\frac{d s}{d t}=k_{s}\left(s-s_{\infty}\right)$ 
Integration of the equation (1) with appropriate boundary conditions, results into following equation:

$\ln \frac{s_{t}-s_{\infty}}{s_{0}-s_{\infty}}=-k_{s} t$

Where,

$\mathrm{S}_{\mathrm{o}}=$ Inherent sodium content of turkey breast meat

$\mathrm{S}_{\mathrm{t}}=$ Sodium content of turkey breast meat at particular treatment parameter

$\mathrm{S}_{\infty}=$ Sodium content of turkey breast meat at saturation point

$\mathrm{t}=$ Time

$\mathrm{k}_{\mathrm{s}}=$ Sodium mass transfer coefficient

The experimental data was fitted in equation (2) to calculate $\mathrm{k}_{\mathrm{s}}$ values for different sodium salts. This analysis follows Fick's second law for unsteady state mass transfer. The other assumptions include negligible surface resistant between product (Lenart \& Flink, 2007) and surface and constant concentration of osmotic solution during the experiment ((Hinkley et al., 2015). Constant concentration of osmotic solution was achieved my employing larger sample to solution ration (1:10) and higher concentration of the osmotic solution $(0.86 \mathrm{M} / \mathrm{l})$. Agitation rate of $70 \mathrm{rpm}$ in a water bath was applied to minimize surface resistant.

\subsubsection{Sodium content of turkey breast meat at saturation point}

In order to obtain mass transfer coefficient, sodium content at saturation level for turkey breast meat was required to find out. The experiments to find out the saturation 
level values were conducted separately at room temperature with the same experimental parameters. The meat cubes were thawed, dried and weighed. Appropriate amount of $0.86 \mathrm{M} / \mathrm{L}$ salt solution was measured out in a $400 \mathrm{ml}$ Erlenmeyer flask. Sample to solution ratio of 1:10 was maintained to create enough concentration gradient. The cubes were dropped into the solution and shook well. The experiment was conducted for 48 hours at room temperature. $1 \%$ potassium permanganate was added into the solution at the beginning of the experiment to suppress the microbiological activity. At the end of the experiments, the samples were taken out of the solution, rolled over to an absorbent paper to absorb excess salt solution from the surface of the meat and weighed again. The samples and the test solution were analyzed for sodium content using ISE. The tests were performed in triplicates and sodium analysis for each replicate was performed duplicate and the mean values were reported. The sodium content of the meat at saturation level was $1256 \mathrm{mg} / 100 \mathrm{~g}$. This value was used in the equation described about to determine sodium diffusion coefficient.

\subsection{Determining the effects of different sodium salts having anion larger than sodium chloride on sodium diffusion}

\subsubsection{Introduction}

As discussed in previous chapters, considerable amount of efforts has been made by several researchers in finding an alternative or way to reduce sodium in the processed food products without affecting the sensory parameter. Several of them are successful and used in the food industry in some capacity. However, there is still a huge requirement from the food industry as a unique solution of this problem. 
Our research focuses on partially replacing sodium chloride with other sodium cation additives which has associated anion larger than chloride in sodium chloride. Using a compound with larger anion size makes the overall molecule size larger. This research study focuses on the reducing sodium diffusion rates during thermal application. Since, larger molecules have tendency to diffuse slower in the semipermeable food matrix systems, using sodium salts having larger molecular size due to larger anion in combination with sodium chloride might result in to lower sodium diffusion rates in turn lower sodium contents in the final product.

\subsubsection{Materials and method}

Two phosphates, one sulfate and one protein salt was selected in this study. Reagent grade monosodium phosphate (Fisher Scientific, Fair Lawn, NJ, USA), sodium tripolyphosphate (Fisher Scientific, Fair Lawn, NJ, USA), sodium sulfate (Fisher Scientific, Fair Lawn, NJ, USA) and monosodium glutamate (Sigma-Aldrich, St. louis, MO, USA) were studied (Hinkley et al., 2015). Additionally, combination of equal molar ratio (50:50) of sodium chloride and sodium phosphate was also investigated.

The amount required to achieve equal molar concentrations as that of sodium chloride was calculated $(0.86 \mathrm{M} / \mathrm{l})$ for each compound. The solutions were made using distilled water and necessary $\mathrm{pH}$ adjustments were made using potassium hydroxide (Fisher Scientific, Fair Lawn, NJ, USA) and acetic acid (Fisher Scientific, Fair Lawn, NJ, USA) to maintain $\mathrm{pH}$ between 6.5 to 7 in order to implement consistent experimental condition for all the experiments. 
The experiments were conducted in a same set up and environment as previous other experiments. These experiments were conducted only at $90^{\circ} \mathrm{C}$ and $1: 10$ sample to solution ratio was maintained to generated enough concentration gradient. Experiments for each compound was conducted separately in triplicate and duplicate measurements were noted for each experiment. The appropriate amount of solution was measured out in a $400 \mathrm{ml}$ Erlenmeyer flasks and kept in a hot water bath adjusted at $90^{\circ} \mathrm{C}$. Once the temperature of the solution reached to $90^{\circ} \mathrm{C}$, the meat cubes were dropped into the flasks. The flasks were closed with a loose stopper to avoid change in solution concentration due to solvent evaporation and shook well. Agitation speed of 70 oscillations was adjusted to reduce temperature and solute gradient. Samples were taken out at every 20,40, 60 and 100 minutes. Immediately after taking out, samples were rolled over an absorbent paper to remove excess solution from the surface. The samples were then allowed to cool down for at least 30 minutes and sodium content was analyzed using Ion Selective Electrode.

\subsubsection{Results and discussion}

Figure 4.1, 4.2 and 4.3 shows comparison between sodium content of samples processed in different sodium salt solutions and in sodium chloride solution of equal molarity. Figure 4.1 represents sodium content of samples processed in $0.86 \mathrm{M} / 1$ of sodium chloride, sodium phosphate and the sodium tripolyphosphate. Figure 4.2 shows the comparison of sodium content of samples processed in sodium sulfate and monosodium glutamate with that sodium chloride. Whereas, figure 4.3 compares result from sodium chloride treatment to sodium phosphate and a combine equal molarity (50:50) treatment of sodium chloride and sodium phosphate. The results obtain from these sodium salts were significantly lower than sodium chloride treatment. Table 4.1 
shows percent reduction in the sodium content of final product processed in different sodium salts compared to sodium chloride treatment. ANOVA test was conducted on the data range in SAS and results showed that the data was statistical different at $95 \%$ confidence level $(\mathrm{p}<0.05)$.

Sodium mass transfer coefficient was calculated from these data using the equation (2) described above. As explained by Fick's second low, the diffusion was time dependent and the sodium mass transfer coefficient reduced over a processing span of 100 minutes. Table 4.2 shows $\mathrm{k}_{\mathrm{s}}$ values for different sodium salt treatments over a processing time of 100 minutes. The $\mathrm{k}_{\mathrm{s}}$ values of the compound having larger anions is significantly lower than $\mathrm{k}_{\mathrm{s}}$ values of sodium chloride treatment.

\subsubsection{Statistical analysis}

Statistical analysis was conducted using SAS (SAS institute Inc., cary, NC, USA) software at $95 \%$ confidence level to analyses sodium content data in finished product, sodium mass transfer coefficient results and texture profile analysis data. T-test, ANOVA, Duncan and Dunnett tests were performed to analyze different data sets. Significant difference in the means were determined by the least significant difference $(\mathrm{p}<0.05)$. Experimental data of each analysis ae plotted as the average of 3 replicates with error bars representing standard deviation. 


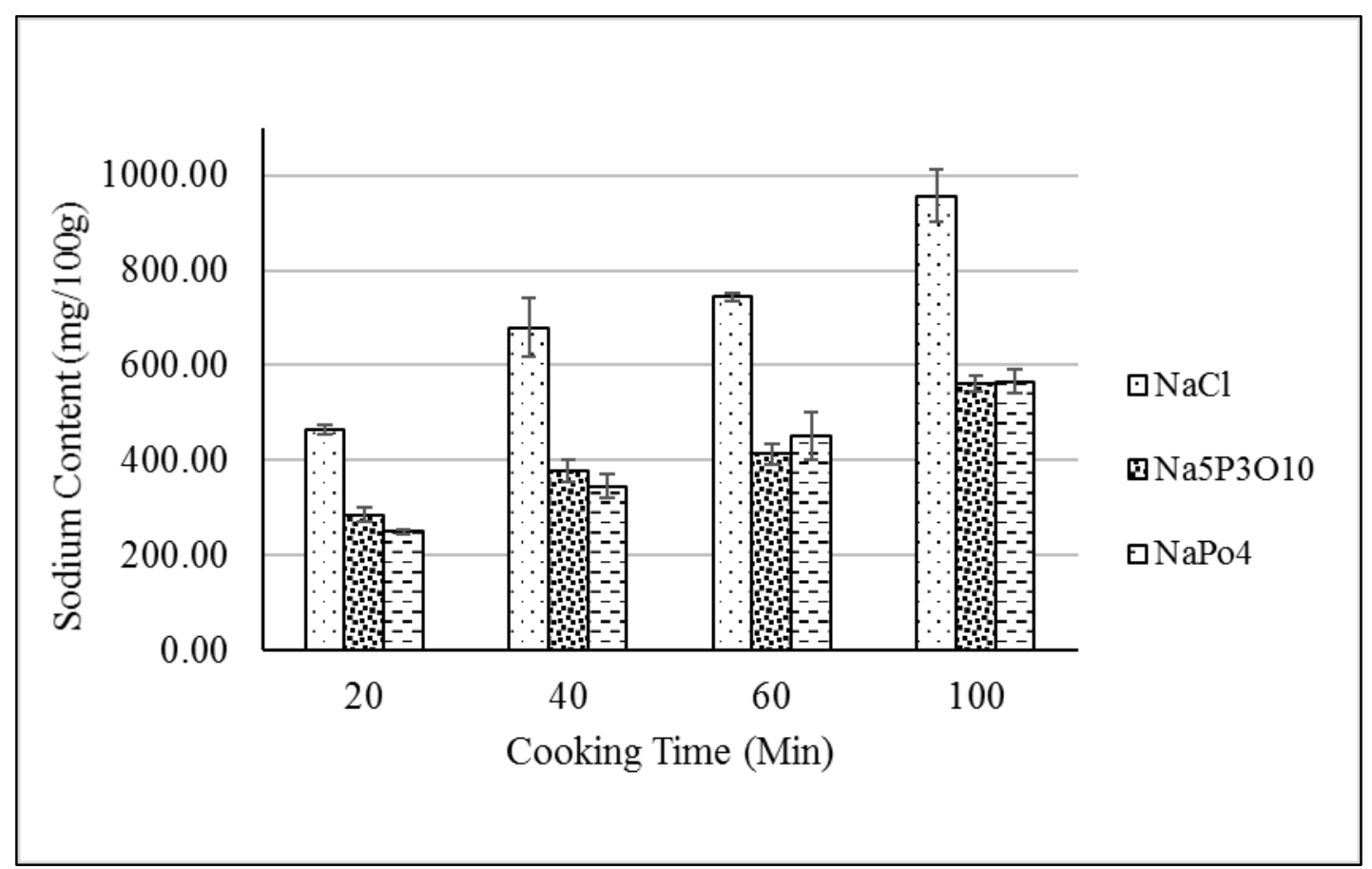

Figure 4.1. Comparison Sodium content of turkey breast meat processed in 0.86 M/l sodium chloride, sodium Tripolyphosphate and sodium phosphate solutions at $90^{0} \mathrm{C}$ 


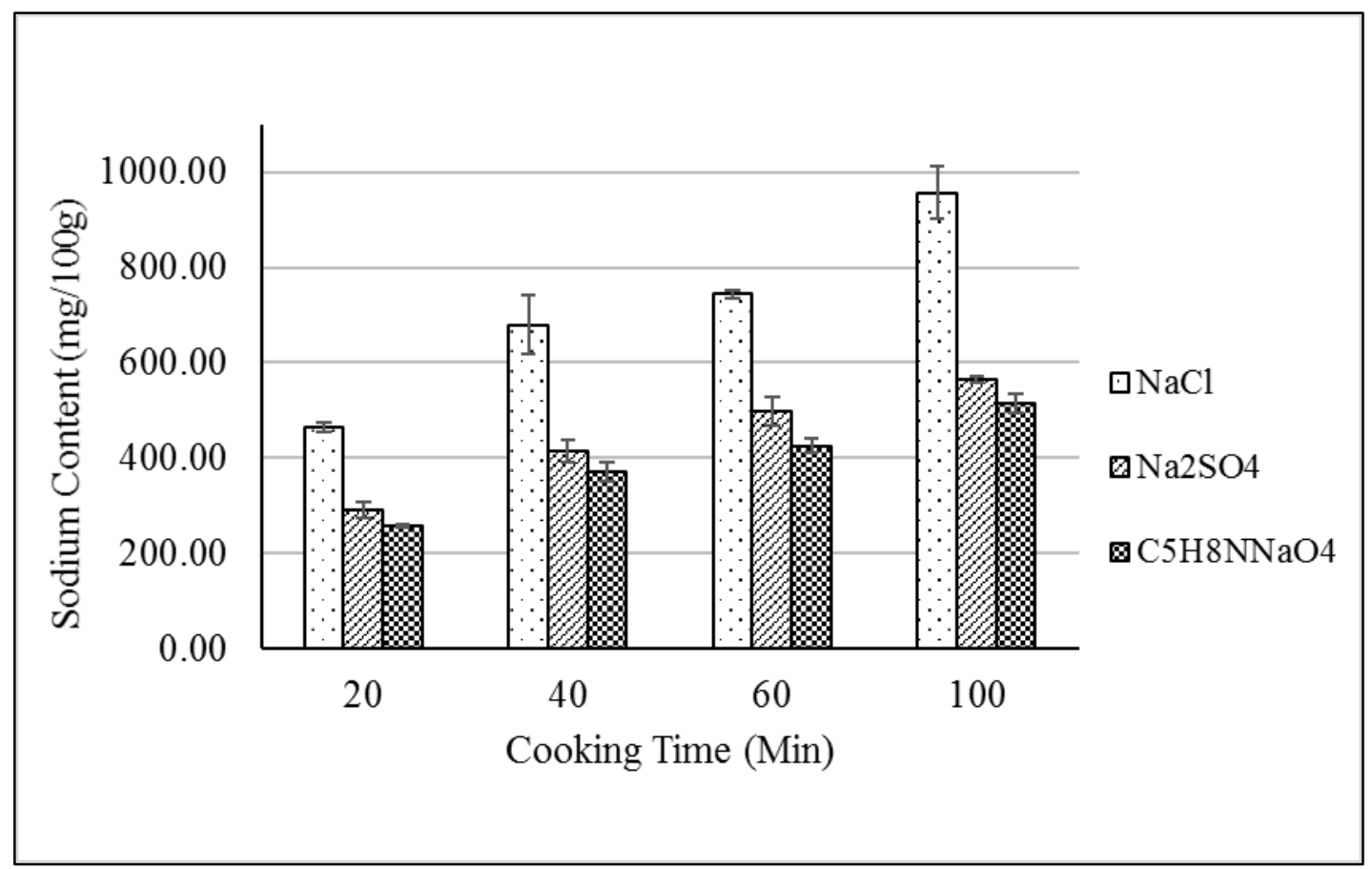

Figure 4.2. Sodium content of turkey breast meat processed in $0.86 \mathrm{M} / 1$ sodium chloride, sodium sulfate and monosodium glutamate solutions at $90^{\circ} \mathrm{C}$ 


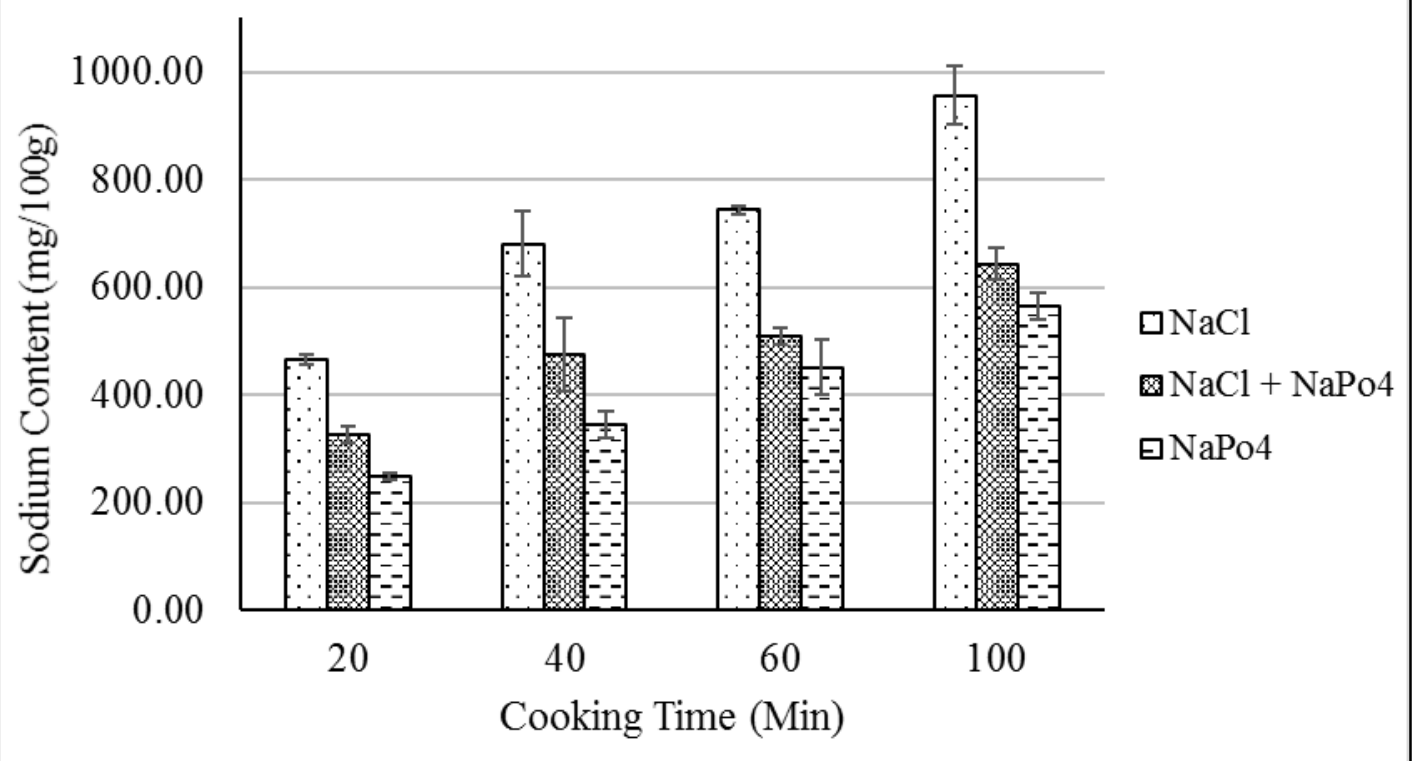

Figure 4.3. comparison of sodium content of turkey breast meat processed in 0.86 M/1 sodium chloride, sodium phosphate and 50:50 ratio of sodium chloride and sodium phosphate at $90^{\circ} \mathrm{C}$

\begin{tabular}{|l|c|}
\hline \multicolumn{1}{|c|}{ Type of treatment } & \% reduction \\
\hline Sodium phosphate & 40.97 \\
\hline 50:50 Sodium chloride and sodium phosphate & 32.72 \\
\hline Sodium Tripolyphosphate & 41.18 \\
\hline Sodium sulfate & 40.87 \\
\hline Monosodium glutamate & 46.10 \\
\hline
\end{tabular}

Table 4.1. Percentage reduction in the sodium content of final product processed in different sodium salt solutions than that of processed in sodium chloride solution 


\begin{tabular}{|c|c|c|c|c|c|c|}
\hline Time (Min) & NaCl & $\mathrm{NaPO}_{4}$ & $\mathbf{N a C l + N a P O} 4$ & $\mathrm{Na}_{2} \mathrm{SO}_{4}$ & $\mathrm{Na}_{5} \mathrm{P}_{3} \mathrm{O}_{10}$ & $\mathrm{C}_{5} \mathrm{H}_{8} \mathrm{NNaO}_{4}$ \\
\hline $\mathbf{2 0}$ & 0.020 & 0.009 & 0.013 & 0.011 & 0.010 & 0.009 \\
\hline $\mathbf{4 0}$ & 0.018 & 0.007 & 0.011 & 0.008 & 0.007 & 0.008 \\
\hline $\mathbf{6 0}$ & 0.014 & 0.007 & 0.008 & 0.010 & 0.006 & 0.006 \\
\hline $\mathbf{1 0 0}$ & 0.014 & 0.006 & 0.007 & 0.005 & 0.005 & 0.005 \\
\hline
\end{tabular}

Table 4.2. Mass transfer coefficient, $\mathrm{k}_{\mathrm{s}}\left(\mathrm{min}^{-1}\right)$ values of turkey breast meat at various time points during processing at $90^{\circ} \mathrm{C}$ in different sodium salt solutions

\subsection{Texture Analysis}

\subsubsection{Introduction}

A texture analysis study was conducted on samples processed in sodium chloride and 50:50 molar ration concentration of sodium chloride and sodium phosphate solutions to determine textural difference in them. Since sodium phosphate is widely used in meat industry as an additive and does not have any clear aftertaste, it can be combined with sodium chloride and might have a potential to be used as sodium chloride replacement. In order to determine its potential to be used as a replacer it is necessary to examine consumer aspects of it. One of the important criteria is textural changes. Texture of meat is one of the important characteristic as consumer acceptance point of view. Texture analysis was conducted to determine the structural difference between samples cooked in sodium chloride solution and in 50:50 combination of sodium chloride and sodium phosphate. 


\subsubsection{Materials and method}

Texture analysis study was performed on INSTRON 5542 (Instron Inc., Canton, MA, USA). The samples were processed in sodium chloride and 50:50 molar ratio solution of sodium chloride and sodium phosphate at $90^{\circ} \mathrm{C}$ for 40 minutes. After taking them out of the solution, meat cubes were rolled over an absorbent paper to remove extra surface moisture and were allowed to cool for 30-45 minutes before analyzing. The samples were compressed (50\% compression) on a non-lubricant plate. Flat disc probe with $50 \mathrm{~mm}$ diameter was used for the analysis. Texture analysis was done perpendicular to the muscles fiber orientation (Villacis et al., 2007). The samples were held hat 50\% compression for 120 seconds. Maximum pressure and residual force values were considered. The values were converted and reported in pressure $(\mathrm{kPa})$.

\subsubsection{Results and discussion}

Figure 4.4 compares the data of texture analysis of samples processed in sodium chloride and 50:50 combination solution with sodium phosphate. Maximum pressure in the figure represents pressure required to take a first bite of the meat which is referred to hardness of sample. Whereas residual pressure refers to the chewiness of the sample. The analysis was conducted in triplicate and the mean values were reported. T-test was conducted on both the datasets to see if there was any statistical difference. At $95 \%$ confidence level, there was no statistical difference found in both maximum and residual pressure values $(\mathrm{p}>0.05)$. That interprets that both the samples did not have any significant difference in their overall texture profile. 


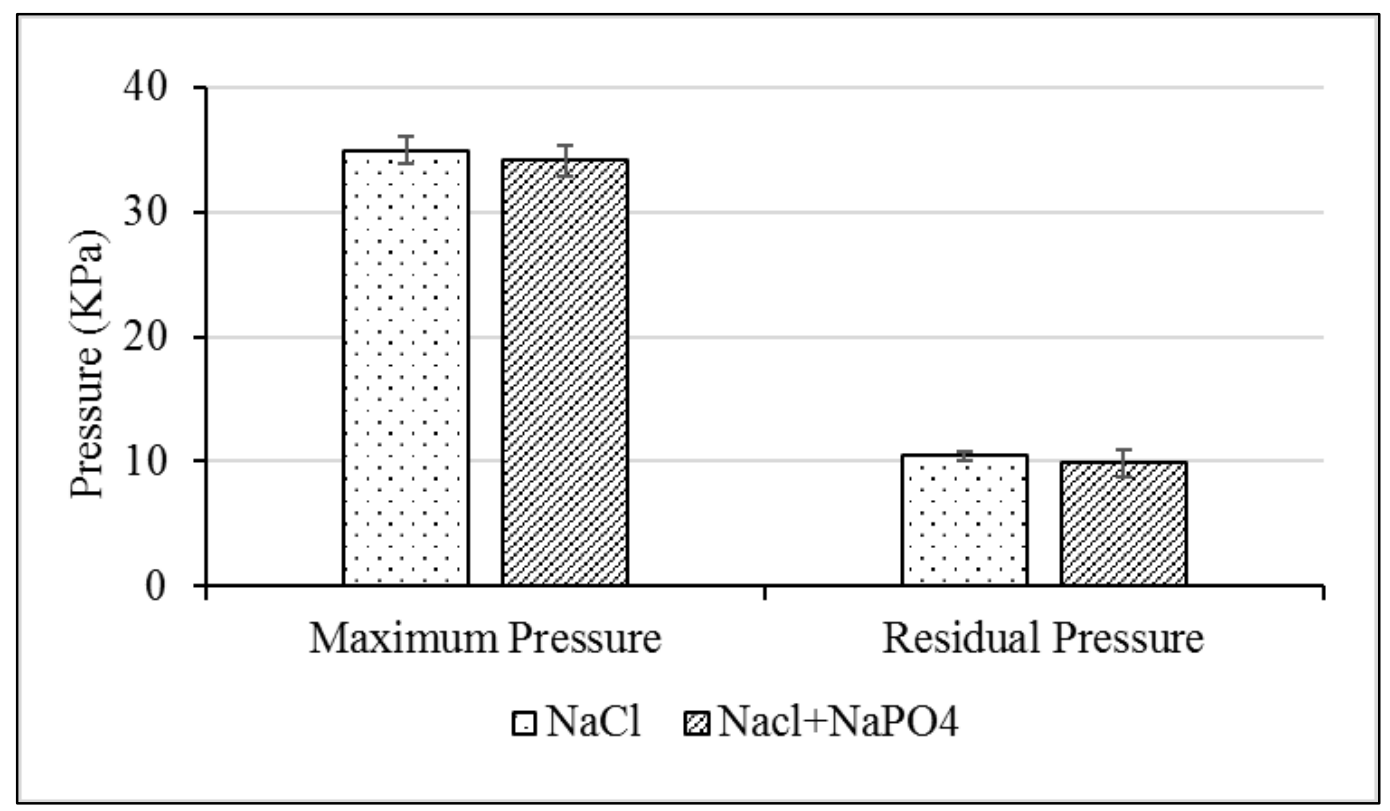

Figure 4.4. Texture profile analysis of turkey breast meat processed at $90^{\circ} \mathrm{C}$ for 40 minutes in sodium chloride and 50:50 molar ratio solution of sodium chloride and sodium phosphate

\subsection{Sensory Analysis}

\subsubsection{Materials and method}

A brief sensory analysis was conducted on the turkey breast meat samples cooked in 0.86 M/l sodium chloride, sodium phosphate and 50:50 combination of sodium chloride and sodium phosphate solutions. 1x1x1 inch turkey breast meat cubes were cooked in respective solutions at $90^{\circ} \mathrm{C}$ for 40 minutes. The test objective was to identify the saltiness difference, sample preference and the recognition of any aftertaste in the samples. The analysis was conducted with participant size of 10. Participants were presented with three samples in random order and were asked to identify the samples from saltiest to least salty scale. They were also asked to identify the sample they preferred most and if there was any aftertaste in the samples. 


\subsubsection{Results and conclusion}

The results showed that $40 \%$ of the subjects rated samples cooked in 50:50 combination solution as the saltiest and rest $60 \%$ reported sample cooked in sodium chloride solution as the saltiest. $70 \%$ of the total participants preferred samples cooked in the combination solution over the ones cooked in sodium chloride or sodium phosphate. Majority of the subjects did not identify any noticeable aftertastes in any of the samples except one subject reported the sample cooked in combination solution had metallic aftertaste. Overall, the study showed positive results and $70 \%$ participants preferred samples cooked in the combination solution of sodium chloride and sodium phosphate over the ones cooked in regular salt solution. The samples cooked in just sodium phosphate solutions were least preferred. A statistical analysis (ANOVA test) was performed on of the saltiness dataset obtained from the participants and the results showed no significant difference in the saltiness between the samples cooked in combination solution and sodium chloride solution. 


\section{CHAPTER 5}

\section{CONCLUSION AND FUTURE WORK}

\subsection{Conclusion}

In summary, this study showed promising results for using different sodium salt species as a partial replacement of sodium chloride as a potential sodium reduction strategy. The First part of the study investigated the effect of temperature and protein denaturation on diffusion rates, the results concluded that there was no significant decrease or increase in the sodium content of the final products processed at 4, 23, 50, 70 and $90^{\circ} \mathrm{C}$ for 160 minutes.

The second part of this study investigated effect of sodium cation compound having relatively larger associate anion than chloride in table salt on sodium diffusion rates and sodium content of final product. The study shows 40 to $46 \%$ lower sodium content in the final products processed in different sodium salt solutions in comparison with sodium chloride. On the other hand, 35 to $45 \%$ decrease in the sodium diffusion rates was observed in the samples cooked in different sodium salts solutions then regular table salt treatment. Sodium phosphate in combination with sodium chloride showed promising results with $32 \%$ lower sodium in the final product compared to just sodium chloride treatment.

A texture analysis study conducted on meat cubes processed in sodium chloride solution and a combination solution with sodium phosphate did not show any statistical difference in the both maximum and residual pressure values at $50 \%$ compression. Moreover, $70 \%$ of the participants preferred samples cooked in a 50:50 combination 
solution of sodium and chloride and sodium phosphate solution over separate treatment in a brief in house sensory study No aftertaste was detected by $90 \%$ of participants in samples cooked in the combination with sodium phosphate.

Thus, this study shows potential opportunity of using different sodium cation compounds with relatively larger anion as a partial salt replacer in order to reduce total sodium content in processed meat products.

\subsection{Future Work}

In the current model food system research, a systematic sensory study with large number of participants should be conducted to further investigate consumer preference of sodium phosphate and sodium chloride combination on a larger scale. Also, a synergistic combination of sodium chloride with different other sodium salts can should be investigated to identify potential other compounds which may help further reduce the sodium diffusion rates. The replicate of this study can also be conducted in vegetable protein model to develop sodium reduction strategies in processed and canned beans. 


\section{BIBLIOGRAPHY}

AHA. (2015). Processed foods: Where is all that sodium coming from? American Heart Association.

AHA. (2016). Sodium and your health. Retrieved from https://sodiumbreakup.heart.org/sodium_and_your_health

Arnason, A. (2015). Why processed meat is bad for you. Kopavogur, Iceland: Authority Nutrition.

Beauchamp, G., Bertino, M., \& Engelman, k. (1987). Failure to compensate decreased dietary sodium with increased table salt usage. The Journal of the American Medical Association, 258(22), 3275-3278.

Braverman, J. (2016). Naturally occurring sodium in meat. Retrieved from http://healthyeating.sfgate.com/naturally-occurring-sodium-meat-10826.html

Busch, J. L. C. H., Youg, F. Y. S., \& Goh, H. M. (2013). Sodium reduction: Optimizing product composition and structure towards increasing saltiness perception. Trends in Food Science and Technology, 29, 21-34.

CDC. (2012). GET THE FACTS: Sodium's role in processed food. Centers for Disease Control and Prevention.

CDC. (2016). Sodium: The facts. Centers for Disease Control and Prevention (CDC). 
CDC. (2013). Trends in the prevalence of excess dietary sodium intake - united states, 2003-2010. (No. 62/50). Atlanta, GA: Center of Disease Control and Prevention.

CMC. Sodium in processed meat products. Ottawa, Ontario: Canadian Meat Councile.

Cook, N., Cutler, J., Obarzanek, E., Buring, J., Rexrode, K., Kumanyika, S., Whelton, P. (2007). Long term effects of dietary sodium reduction on cardiovascular disease outcomes: Observational follow-up of the trials of hypertension prevention (TOHP). British Medican Journal.

FDA. (2016). Sodium in your diet: Use the nutrition facts label and reduce your intake. U.S. Food and Drug Administration.

Geller, M. (2011). Campbell adds salt to spur soup sales. Reuters.

Graiver, N., Pinotti, A., Califano, A., \& Zaritzky, N. (2006). Diffusion of sodium chloride in pork tissue. Journal of Food Engineering, 77(4), 910-918.

Graiver, N., Pinotti, A., Califano, A., \& Zaritzky, N. (2009). Mathematical modeling of the uptake of curing salts in pork meat. Journal of Food Engineering, 95(4), 533540.

Hinkley, T., Pandya, J., Kinchla, A., \& Decker, E. (2015). Determination of quantitative sodium mass transfer coefficient during osmotic processing of potatoes. Journal of Food Processing and Preservation, 40(5), 963-968. 
Hooper, L., Bartlett, C., Smith, G., \& Ebrahim, S. (2002). Systematic review of long term effects of advice to reduce dietary salt in adults. British Medical Journal, 325(7365), 628-632.

Lenart, A., \& Flink, J. (2007). Osmotic concentration of potato. International Journal of Food Science and Technology, 19(1), 45-63.

Liem, D., Miremadi, F., \& Keast, R. (2011). Reducing sodium in foods: The effect on flavor. Nutrients, 2072(6643), 694-711.

Meyer, k., Harnack, L., Luepker, R., Zhou, X., Jackobs, D., \& Steffen, L. (2013). Twenty-tow-year population trends in sodium and potassium consumption: The Minnesota heart survey. Journal of American Heart Association, 2(5), 1-9.

National turkey foundation. (2014). 2014 annual report. National Turkey foundation.

Rastogi, N., \& raghavarao, K. (2004). Mass transfer during osmotic dehydration of pineapple: Considering fickian diffusion in cubical configuration. LWT - Food Science and Technology, 37(1), 43-47.

Satin, M. (2014). History of salt consumption. Florida: The Salt Institute.

Shepherd, R., Wharf, S., \& FARLEIGH, C. (1989). The effect of a surface coating of table salt of varying grain size on perceived saltiness and liking of pate. International Journal of Food Science and Technology. 
Strazzullo, P., D’Elia, L., Kandala, N., \& Cappuccio, F. (2009). Salt intake, stroke, and cardiovascular disease: Meta-analysis of prospective studies. British Medical Journal, 339, 1-9.

Telis, V., Romanelli, P., Gabas, A., \& Telis-Romero, J. (2003). Salting kinetics and diffusivities in farmed Pantanal caiman muscle. Pesquisa Agropecuária Brasileira, 38(4), 529-535.

Tornberg, E. (2005). Effects of heat on meat proteins - implications on structure and quality of meat products. Meat Science, 70(3), 493-508.

USDA. (2015). Dietary guidelines for Americans 2015-2020. U.S. Department of Agriculture.

Villacis, M., Rastogi, N., \& Balasubramaniam, V. (2007). Effect of high pressure on moisture and $\mathrm{NaCl}$ diffusion into turkey breast. LWT - Food Science and Technology, 41(5), 836-844.

Volpato, G., Mechielin, E., Ferriera, S., \& Petrus, J. (2007). Kinetics of the diffusion of sodium chloride in chicken breast (pectoralis major) during curing. Journal of Food Engineering, 79(3), 779-785.

Voutila, L., Ruusunen, M., Jouppila, K., \& Puolanne, E. (2009). Thermal properties of connective tissue in brest and leg muscles of chickens and turkeys. Journal of the Science of Food and Agriculture, 89(5), 890-896. 
Wright, D., Leach, I., \& Wilding, p. (1977). Differential scanning colorimetric studies of muscle and its constituent proteins. Journal of the Science of Food and Agriculture, 28(6), 577-564. 